\title{
Rio Grande do Sul no nascer do século XX: Jaguarão e a fronteira brasileira pelos olhos de um padre belga
}

\author{
Rio Grande do Sul at the birth of the $20^{\text {th }}$ century: \\ Jaguarão and the Brazilian border through the \\ eyes of a Belgian priest
}

\author{
Beatriz Ana Loner* \\ Lorena Almeida Gill**
}

\begin{abstract}
Resumo: Este artigo trata do relato do missionário Thomas Schoenaers, da ordem dos Premonstratenses sobre sua estadia no Brasil (1901-1904), em Jaguarão e seu trabalho como professor. Em sua narrativa, comenta fatos significativos sobre a cultura, hábitos, educação e transportes no estado gaúcho. Fascinado pela fauna, geologia e geografia, deixou boas descrições da região da campanha gaúcha, bem como uma visão critica sobre os negros e as relações interraciais na região, no início do século XX, tema deste artigo.
\end{abstract}

Palavras-chave: Missionários. Jaguarão. Afrobrasileiros.

Abstract: This article is about the account of the missionary Thomas Schoenaers, of the Premonstratenses order about his stay in Brazil. In his account he talks about significant facts in Rio Grande do Sul's culture, habits, education and transportation. Fascinated by the fauna, flora, geology and geography he left great descriptions of the region of the "campanha", as well as a critical vision about black people and inter-racial relations in the region, in the early $20^{\text {th }}$ century, which are the theme for this article.

Keywords: Missionary work. Jaguarão. Afrobrazilians.

* Graduada em História pela Universidade Federal do Rio Grande do Sul (1975), mestrado em História pela Universidade Estadual de Campinas (1985) e doutorado em Sociologia pela Universidade Federal do Rio Grande do Sul (1999). Atualmente é professora associada da Universidade Federal de Pelotas.

** Graduada em História (UFPel), Mestre e Doutora em História (PUCRS) e Pós-Doutora pela Università Degli Studi di Siena, Itália. Desde 1992 é professora da Universidade Federal de Pelotas, junto ao Departamento de História e Antropologia. 
Este artigo trata da vinda do missionário Thomas Aquinas Schoenaers, da ordem dos Premonstratenses, conhecida como norbertinos (de São Norberto) e de sua estada de três anos no Brasil, especialmente na cidade de Jaguarão, na fronteira com o Uruguai.

Na escrita de Thomas sobre o Brasil, pode-se dizer que, ao contrário de simplesmente ver, ele olha. Segundo Cardoso (1995, p. 348):

[...] o ver, em geral, conota no vidente uma certa discrição e passividade ou, ao menos, alguma reserva. [...] Com o olhar é diferente. Ele remete, de imediato, à atividade e às virtudes do sujeito, e atesta a cada passo nesta ação a espessura de sua interioridade. Ele perscruta e investiga, indaga a partir e para além do visto, e parece originar-se sempre da necessidade de 'ver de novo' (ou ver o novo), como intento de 'olhar bem'.

Chegando no início do século XX, e aqui permanecendo entre os anos de 1901 e 1904, o padre Thomas deixou descrições muito vivas do país, especialmente do cotidiano e dos costumes da região dos pampas gaúchos, ao olhar cuidadosamente o novo. Sua importância reside em que, na condição de padre, estava particularmente interessado na difusão da religião e da educação, e com isso deixou primorosas leituras dos costumes da região da fronteira sul, comumente não privilegiada nos relatos de viajantes. É claro que sua escrita não é isenta, como nenhuma o é. Suas informações, muitas vezes recheadas de exotismo, pretendiam fazer com que bons cristãos continuassem enviando dinheiro para obras caridosas no além mar.

Vindo apenas uma década depois de vários acontecimentos particularmente marcantes, como a abolição, a proclamação da república e os conflitos republicanos que ensanguentaram o estado, suas observações são também reveladoras sobre as mudanças do período. Fornece, dessa forma, um bom panorama das tensões entre os vários setores políticos e sociais no Rio Grande do Sul naqueles anos, interessando, ainda, à economia seus escritos. De mais a mais, procura descrever, a seu modo, cada uma das cidades pelas quais passou, dentro de sua óptica particular de cidadão europeu, de uma região com pouco contato com os trópicos. Por tudo isso, seu livro, ainda não explorado, é uma fonte preciosa para os historiadores atuais.

Neste trabalho se fará uma introdução aos seus escritos, procurando apresentar uma breve síntese de suas preocupações e detalhar as questões relativas a algumas cidades por onde passou, como Porto Alegre, Pelotas e a própria Jaguarão. Nosso olhar se dirigiu, sobretudo, a aspectos da 
cultura da fronteira, como a religiosidade, a música, cuidados com a saúde e higiene, além da análise sobre as relações entre negros e brancos na região.

Padre Thomas Schoenaers nasceu em 18 de março de 1872, em Helchteren, com o nome de batismo de Gerardus Jozef Schoenaers e ingressou na ordem premonstratense em 1891, ordenando-se em 1897. Tendo assumido sob sua responsabilidade a tipografia da ordem, na Abadia de Averbode, editou o jornal O Mensageiro. Mostrou inclinação para as letras deixando não apenas seus dois tomos com as cartas das viagens ao Brasil, mas também artigo e drama histórico sobre a vida de São Norberto. No Brasil residiu vários anos, inicialmente em Jaguarão e, numa segunda viagem, em Petrópolis, no Colégio São Vicente de Paulo, exercendo inclusive o cargo de reitor do estabelecimento. No início da Primeira Guerra seguiu para seu país, servindo como capelão militar durante a guerra e recebendo a Cruz do Mérito Militar, por sua atuação. Morreu em novembro de 1919, de câncer, tendo sido enterrado na Abadia de Averbode ${ }^{1}$.

Seu livro sobre a primeira viagem ao Brasil foi publicado na Bélgica em maio de 1904, todavia, sua versão em português ocorreu exatos 99 anos depois, devido ao esforço e paciência de Eduardo Álvares de Souza Soares, o qual, com muita persistência, conseguiu uma cópia de seus escritos e, a partir daí, empreendeu, como ele mesmo avalia, uma verdadeira cruzada com o objetivo de conseguir a tradução da obra, o que só veio a ocorrer em 1999/2000, com a colaboração do médico Cornelis Christiaan Van Ommeren, belga, mas que veio ao Brasil com sua família e aqui fez seus estudos. Com os últimos três anos antes de sua edição absorvidos pela tarefa de dar forma e atualização literária à obra, finalmente ela foi publicada pela editora da Universidade Católica de Pelotas, infelizmente numa edição de apenas 200 exemplares, ao que consta.

O livro é composto por 59 cartas, escritas ao sabor dos acontecimentos e enviadas para a Abadia, sendo ali publicadas regularmente no jornal O Mensageiro. Os objetivos do padre Thomas não eram apenas de descrever e compartilhar com seus conterrâneos e outros religiosos as narrações sobre uma terra desconhecida, no entanto, também de conseguir apoio da comunidade católica belga para a vinda de mais padres e a remessa de recursos para as obras no Brasil. Desta forma, ao

Todos os dados sobre sua vida e obra foram retirados do prefácio de seu livro (p. 8 a 27), redigido por Eduardo Álvares de Souza Soares, do Instituto Histórico e Geográfico de Jaguarão. 
seu olhar de estrangeiro e militante católico, deve-se acrescentar também aquele do propagandista das missões belgas em terras brasileiras, com o intuito de demonstrar sua importância e a necessidade da continuação de tal obra.

Munidos dos necessários esclarecimentos sobre o contexto das cartas, pretende-se agora acompanhar o padre Thomas em suas primeiras andanças em terras brasileiras, nas quais ele chega pelo porto de Salvador, Bahia. Dele, nos traz impressões marcadas pelo exotismo da visão de muitos trabalhadores negros a transportar mercadorias, vender produtos e animais de pequeno porte e buscar serviços junto aos passageiros de seu navio. Após um rápido passeio pela cidade e uma visita ao convento dos franciscanos, retorna ao navio para prosseguir viagem. No porto do Rio de Janeiro, a demora é de vários dias para o descarregamento das mercadorias, o que permite fazer alguns comentários sobre a cidade e o porto, admirado pela sua magistral beleza, em meio a um curioso piquenique no Corcovado, já com o bondinho em funcionamento, mas sem o Cristo. Em Santos, final da primeira etapa de sua viagem, padre Thomas e seus dois colegas seguem para o interior, em visita a um estabelecimento da ordem, o colégio de Pirapora. Neste ponto, o transporte em carroças "brasileiras", sobre as quais sentia muita curiosidade, lhe proporciona a mais agradável experiência da viagem.

Depois de alguns dias de descanso, aproveitados para conhecer o local e sua fauna, segue viagem para o Rio Grande do Sul, a bordo do vapor Santos, apinhado de passageiros. Passando por Desterro, fica tentado a lá permanecer, devido às insistências do padre alemão que o recebeu ali e a necessidade de mais religiosos para o serviço.

Finalmente chega à costa gaúcha, desembarcando em Rio Grande, cidade da qual não guarda boa impressão, nem do hotel, nem daqueles que encontrou, vistos com suspeição, passando o último dia a bordo do vapor Juncal, antes da partida. Depois de ainda enfrentar uma tormenta em plena Lagoa Mirim, consegue desembarcar em Jaguarão, no dia 11 de maio, tendo então completado uma viagem de 73 dias desde seu país. Imbuído de sentimentos puros e tendo chegado com boa saúde, estava cheio de esperanças com relação à sua nova morada e seus habitantes.

\section{Primeiras impressões do novo mundo}

Quando chega, ocorre um hiato em sua correspondência, provavelmente provocados pelas necessidades de aclimatação à nova realidade. Sua próxima carta seria escrita um mês depois, talvez devido 
a seus vários compromissos e à estafa da viagem. Provavelmente, também porque necessitou digerir várias realidades da vida daquela nova e estranha cidade, antes de resolver escrever para seus pares sobre ela. Já vimos que suas cartas não poderiam ter o tom de confissão ou de desabafo, mas deveriam ser, sobretudo, educativas e com o sentido positivo para a congregação. No colégio Espírito Santo, em Jaguarão, padre Thomas lecionava matemática e esgrima, entretanto, sua atenção dirige-se a todos os aspectos da vida na cidade.

Coerente com seus objetivos, quando volta a escrever, em 9 de julho de 1901, sua nona carta é dedicada aos aspectos religiosos da cidade, na qual, segundo ele, imperavam superstições infantis e uma profunda irreligiosidade, embora todos se considerassem bons católicos. Em relação ao catolicismo, são muitos os trechos em que deplora os aspectos apenas formais e suntuosos dos cultos e das procissões, sem piedade interior. Ele recrimina exacerbado o predomínio maçom na cidade, a permissão de feitiçarias e curandeirismo e como as superstições floresciam devido à ignorância e credulidade da população, que insistia em consultar feiticeiros.

Ainda há espaço, todavia, para falar de curiosidades, como a bateção de manteiga através do galope de animais e a encantada descrição de uma diligência. Deve-se entender que, antes de ingressar na ordem religiosa, o jovem Gerardus pensava também em ser militar e teve formação neste sentido. Assim, era um apaixonado por cavalos, muito caros em sua terra, acessíveis a qualquer pessoa em Jaguarão. Em vários trechos das cartas, ele deixa claro seu encantamento por todas as formas de tração animal e sua admiração pelos gaúchos, os mais hábeis cavaleiros que já vira. Alguns de seus poucos momentos de lazer são os passados em fazendas e caçadas nos arredores da cidade, nas quais faz uma coleção de pedras e esqueletos de animais.

Contudo, sua atração pelas diligências vai desaparecer completamente a partir da primeira viagem que é obrigado a fazer em uma delas, no caminho que ligava Jaguarão a outras cidades, pois lhe parecerá uma "câmara de torturas" destinada a vergastar seus passageiros e arriscar suas vidas, especialmente ao cruzar as valas de rios e arroios, ainda sem pontes. Em outras viagens, em veículos semelhantes, sofrerá até acidentes, como um tombamento e procurará evitá-las o máximo possível. Sua curiosa descrição de como os viajantes deveriam se inclinar para o lado oposto do veículo, para evitar acidentes, parecenos hoje dignas de comédias. A viagem de volta, feita a cavalo, por rios e sangas volumosos, devido a chuvas torrenciais, também foi cheia de 
riscos, mas, segundo ele, agradabilíssima, pois permitiram combinar o zelo religioso, motivo da mesma, com uma aventura completa em meio a rios engrossados com águas de mais de um metro de altura e montarias irrequietas.

\section{Os negros}

Ao contrário de outros viajantes, Padre Thomas não apresenta sentimentos de aversão ou racismo em relação aos negros. Há uma estranheza inicial, após uma primeira visão em Salvador, descrita em tons fortes pela singularidade de suas faces e aparente comicidade de suas roupas ante seus olhos:

É um espetáculo que a nós, europeus, demasiadamente chama a atenção, eis que aqui e ali há um negro ou negra, vestidos como os homens e mulheres de Bruxelas ou Antuérpia. Minha gente! Tive de fazer força para não rir quando, vez por outra, encontrava tais pessoas, usando vestes notoriamente caras, às vezes, toda de seda branca, emoldurando feições não meio escuras, mas semelhantes a um bolo que, havendo queimado, reveste-se da cor negra mais retinta possível, com as mãos descobertas e os pés descalços (meias e calçados parecem ser desconhecidos) (p. 82).

No porto do Rio de Janeiro, observou o serviço do descarregamento, feito por negros e mulatos sob o comando de um "capitão" também negro, que impressionava pelo porte de quase dois metros e pela agressividade com seus subordinados, a exigir maiores esforços e agilidade, com uma adaga na cintura ou na mão, como presenciou ${ }^{2}$.

Já nesse momento, Thomas demonstrou surpresa pelos grandes esforços despendidos pelos trabalhadores negros, comparando-os lisongeiramente com aqueles de seu país, eis que sua força "convenhamos, é maior do que a dos nossos portuários de Antuérpia, pois costumeiramente mantêm sobre os ombros musculosos não menos que 120 quilos" (p. 91). Avaliando incorretamente sua alimentação como carente, devido a consistir apenas em sopa, feijão, arroz e peixe, considera que sua energia para o trabalho vem de estarem longe de bebidas e princípios socialistas, que corrompem, na visão do padre, os

2 Este modo de trabalho, naqueles anos, era ainda um resquício do tempo da escravidão, com os trabalhadores dividindo-se em "tropas", comandadas por um capitão. A partir delas, desenvolveram-se o modo de trabalho em turmas, posteriormente controladas pelo sindicato. Sobre esta forma de trabalho, veja-se CRUZ, 2000, p. 243-290. 
trabalhadores europeus. Seu ódio aos socialistas não merece surpresa, mas chama a atenção a não detecção da bebida como um problema aos trabalhadores brasileiros, ao contrário de vários outros viajantes.

Mais tarde, em Jaguarão, ele pouco falará de bebidas, citando apenas um empregado negro do colégio com esse vício. Entretanto, recriminará severamente as vendas de esquinas e aos portugueses que as exploram, como local de bebedeiras e tumultos. De outro lado, nada há em seu relato o ranço sobre negros bêbados, que domina as descrições dos europeus que andaram nestas terras no século XIX. Em dado momento, inclusive, padre Thomas provoca risos, ao dizer que, após os religiosos serem homenageados com uma retreta, por uma banda de negros, o Prior os convidou para entrar e tomar uma cerveja, o que Thomas achou uma temeridade, pois não tinham muito da bebida na casa. Em que pesem seus temores, vinte músicos, admiravelmente, beberam apenas o conteúdo de três garrafas: "de cinco a seis deles bebiam no mesmo copo e declaravam-se satisfeitos. Observe então que Baco, aqui, não tem adeptos e que a miserável embriaguez, com sua trajetória de mazelas, não encontra domicílio"' , conclui o satisfeito sacerdote, não sem antes dizer que, caso fossem músicos belgas, seria necessário um barril. Embora nos pareça claro que houve o estranhamento da bebida, por parte dos músicos, ou uma inibição coletiva, pelo receio em contrariar as boas imagens que os negros sabiam que os padres de batina branca tinham deles, não deixa de ser um alívio não ler, mais uma vez, relatos de brasileiros, negros ou brancos, sujos, bêbados e desmazelados, frente a europeus de fino trato, pelo menos no gosto dessas duas pesquisadoras.

Mas o religioso também inova em outras áreas, pois se surpreende com a distância social entre brancos e negros, dizendo que os primeiros procuram enxotar os negros de todas as maneiras, numa atitude de quase vingança pela abolição, evitando qualquer contato entre eles, a ponto de não permitir que participassem do mesmo grupo de orações na Igreja. Simpatizando com estes últimos pelo seu comportamento simples e risonho de agir, sempre atentos aos mínimos gestos dos padres, idealiza formar uma escola para os negros, cujas almas, afirma, de forma culturalmente preconceituosa, "são muito menos negras que as dos brancos" e que demonstram mais interesse em participar das coisas da Igreja (p. 165). Contudo, cumpre estritamente o que lhe é exigido, educando e atuando apenas entre os meninos brancos, sem iniciar nenhuma obra entre os negros, apesar de algumas vezes voltar ao

${ }^{3}$ O título é ainda mais significativo: Sem ébrios (p. 362). 
tema da escola para este grupo, exortando os fiéis belgas a que mandem recursos para isso.

Por um lado, esta pode ser mais uma forma de exortação aos fiéis da comunidade belga, para que auxiliem financeiramente as missões em terras tropicais. De todo modo, os negros lhe ganham suficiente interesse e curiosidade para que nos deixe várias descrições sobre seus casamentos e festas. Especificamente a devoção a Nossa Senhora do Rosário, suas procissões e o relato do comportamento dos afrodescendentes em uma breve entrada na igreja central (aparentemente, não frequentada normalmente por eles), com suas lamúrias aos santos, são oportunidades de ouro para entender aspectos de sua religiosidade.

Ressalta a questão recorrente dos pés no chão, mesmo em momentos solenes como casamentos, o que identificaria um quadro de muita miséria entre os afro-descendentes. Sobre suas ocupações, além do contrabando e dos serviços na pecuária, apresenta uma descrição verdadeiramente sociológica do tratamento recebido pelos agregados e domésticos nas casas da elite. Não deixa de notar sua superioridade numérica e o perigo que poderiam representar aos brancos, caso resolvessem se rebelar. Seu primeiro contato com a famosa "democracia racial" gaúcha dá-se através de uma matrona branca de estância, que defende ardorosamente a ideia de que, no Estado, a escravidão era mais amena do que em outras partes. Após ouvir um discurso da senhora, que insiste em que, já antes da abolição, negros eram muito bem tratados, ele pondera:

Pelo menos nas palavras, a escravidão, aqui, acabou. Mas o será também de fato? Como já me referi, o negro, aqui, é sempre desprezado, um "João ninguém", que, em verdade, quando em vez recebe uma palavra carinhosa, semelhante à que o caçador dirige ao seu cão [...]. Por certo, tenho para mim que a escravidão continua. Fora, necessariamente, o que representa a relação de trabalho entre negro e branco, o desprezo e aversão do último em relação ao primeiro é tão grande e aferível quanto nos tempos de escravatura. Cada família branca, na cidade, tem a seu serviço uma família negra, pais e filhos. Estes têm sua habitação num pequeno prédio, a pelo menos quinze metros da casa dos patrões. Na urbe, quase todas as casas são construídas assim. Na família negra, pai, mãe, filhos e filhas trabalham na casa e no jardim dos patrões e a remuneração consiste em receber alimentação e vestuário (p. 213-214).

Padre Thomas será, para sempre, presa dos olhos negros, de seu aspecto humilde e ansioso por agradar, especialmente aos padres. Assim, 
abordará com muita empatia e sem arrogância os costumes e práticas dos negros, como o terno de reis e a dança do boi bumbá, do qual tirou fotos e oferece bela descrição. Percebe-se, também, que, embora considere os brancos mais bonitos, não desmerece a beleza negra ou mulata, e sempre apresenta estas pessoas com bons olhos e cores.

Nisso difere bastante de vários outros viajantes que já passaram pelo Brasil e que viam no negro pouco mais do que um animal de carga, imerso em malefícios ou superstições. Padre Thomas, ao contrário, vê no grupo, primordialmente, um reduto de boas almas à espera da salvação na palavra de Deus, já que têm medo de que não sejam salvos pela falta de condições.

Entretanto, como um bom europeu, também nos oferece algumas doses do "olhar do estrangeiro", pela incompreensão da hierarquia racial no país, como quando fala do funeral de um venerável maçom, destacando o fato de que era negro, ou quando, ao falar de seus alunos, comenta a respeito de "alguns negros" que havia entre os estudantes, como um educado menino de sete anos, filho do farmacêutico do quartel. Ora, se havia tal preconceito e discriminação aos negros por parte da sociedade de Jaguarão, é obvio que as pessoas de quem fala não eram consideradas pretas naquela sociedade.

\section{O cotidiano da cidade e de seus habitantes}

Outra surpresa, ao lidar com este viajante, é sua descrição dos pequenos, os filhos da elite sul rio-grandense e seus hábitos aristocráticos e arrogantes no trato com os demais, incluindo serviçais ou pessoas de meio social inferior. Além de muito sérios para a idade e sempre tendendo a comportamentos de adultos, os pequenos senhores faziam-se indisciplinados, tanto dentro como fora das aulas. Esse tema é interessante para se pensar que Thomas, muitas vezes, nutria simpatia maior por aqueles que eram desprezados pela maioria da população, ou seja, no que tange às crianças percebia uma precocidade interessante com relação aos negros, os quais montavam bem a cavalo, usavam com destreza as armas, exerciam atividades desde cedo e pareciam não ter nenhum tipo de medo, nem mesmo de cobras. Para ele, essa situação é surpreendente, tanto assim que chega a revelar a vida das crianças na Bélgica, muito protegidos por seus pais.

Ainda que partilhe do conceito de civilização proposto por Elias (1994, p. 23), o qual afirma que: '[...] A sociedade ocidental procura 
descrever o que lhe constitui o caráter especial e aquilo de que se orgulha: o nível de sua tecnologia, a natureza de suas maneiras, o desenvolvimento de sua cultura científica ou visão do mundo, e muito mais', padre Thomas percebia progressos no interior do Rio Grande do Sul, sobretudo na emancipação e autonomia das crianças.

Seu contato prolongado com elas termina por render descrições da infância fora dos grandes centros. Na página 224, vemos que o clima belicoso dos pais rapidamente transfería-se aos filhos, assim, por culpa de uma palavra ofensiva, os padres têm que lidar com um duelo entre três de seus alunos maiores. Como tudo se passa fora do recinto escolar, eles podem aplicar pequenas punições aos duelantes, sem envolverem-se mais profundamente no assunto, do qual, aliás, parecem não querer saber.

O Colégio, a julgar pelas suas cartas, prospera rapidamente e logo são necessários outros alojamentos para alunos e também novas salas de aula, o que dobra o trabalho dos religiosos, que, por outro lado, recebem reforços vindos da Bélgica na figura de outros dois sacerdotes. No segundo ano, já atendem alguns alunos mais velhos, segundo ele, de bigodes e sem dentes. Como faz esta observação muito rapidamente, logo se desviando para outro assunto, deixa este em suspenso. No entanto, mais além, fala da fascinação da população de alta renda por arrancar os dentes para colocá-los de ouro e como isso acontecia mesmo com crianças ainda pequenas, o que pode nos indicar o caminho para este súbito aparecimento de desdentados na cidade. Também relata a vinda de irmãs de caridade, das quais se faz mentor e que se dedicam à educação feminina, conseguindo fazer com que os pais tirem suas filhas da escola protestante, até então a única que dava ensino a mulheres, para o cuidado das freiras.

Uma das partes mais interessantes e valiosas para o estudo do viver comum na cidade é quando o padre resolve descrever, em detalhes, seu passeio diário pelas ruas de Jaguarão. Deve-se primeiro observar que, a partir do segundo ano, ele ainda deve manter o interesse de seu público belga e católico na missão, mas, concomitantemente, está praticamente absorvido pelas tarefas diárias de aulas e eventos, que the tomam o tempo. Dessa forma, mantém viva a atenção do público com a descrição da ronda diária que faz nas ruas da cidade, das quais nos dá interessantes informações, rua por rua do traçado central da cidade e, mais ainda, dos acontecimentos delas, como da passada de uma tropilha a caminho da charqueada, das vendas da esquina e de seus frequentadores, dos 
espetáculos de touros, e também dos circos que volta e meia instalamse na cidade.

Demora-se a falar sobre a mulher brasileira. A branca é vista como indolente, gastando em demasia seu tempo a ficar na janela e observar a rua, invejando tecidos ou jóias das demais e praticamente nada fazendo em termos de trabalho, nem sequer bordados ou outras distrações femininas da época. Sua atenção parece mais endereçada às negras, não em termos libidinosos, mas, sim, com um quase encantamento pela cor e seus costumes. Por conseguinte, tanto fala da linda empregada negra ou mulata e seus vestidos brancos de trabalho doméstico ${ }^{4}$, como das pretas velhas, suas esquisitices, seus cachimbos no canto da boca e suas recriminações na igreja. Mesmo que diga, sobre uma velha de mais de 80 anos, que ela lhe lembra as bruxas de Shakespeare, nota-se uma certa admiração infantil por estes seres tão diferentes. Bem ao início, já havia brindado seus leitores com uma descrição das lavadeiras dos rios, e seu ritual de bater a roupa com tanta força que ele se apieda dos tecidos 5 . Pouco depois, a ida de uma delas a entregar a roupa lavada para os padres, faz ele e seu superior ficarem a contemplála, observando sua curiosidade pela sala em que foi recebida e pelos seus adornos, dos quadros aos objetos que a compõem. Nisto, padre Thomas age como se estivesse frente a um fenômeno desconhecido e que o encanta, talvez como reminiscência de leituras sobre os povos africanos, que, como homem culto e erudito, devia ter feito em sua terra natal.

Há uma simpatia especial pelas negras e mulatas, que ele não estende às brancas, como já vimos, vistas como enfatuadas e negligentes, dadas ao mexerico e ao lazer. No entanto, com relação às negras, entende o verdadeiro drama que estas sofrem com seus cabelos lanosos e curtos, encarapinhados e diferentes dos padrões de beleza, ao mesmo tempo em que descreve as formas pelas quais queriam compensar este problema. Não deixa de acrescentar que, quando estas se portam mal, são levadas à delegacia e têm seus cabelos raspados a zero, como forma de castigo. Ingenuamente, não se pergunta o motivo porque só as moças negras passam por esta provação, mas, a seu favor, veja-se que já havia exposto uma visão bem crítica sobre a pretensa igualdade racial no país. Por fim, ao falar do seu gosto pelas cores alegres, que usam de todas as formas,

\footnotetext{
4 Das quais não deixa de notar a coincidência com as vestes dos padres dizendo que, ao longe podem ser confundidos, numa inconsciente aproximação entre os religiosos e os negros.

5 “impiedosas lavadeiras - Maria preta”, (p. 163) é o título.
} 
especialmente nos vestidos ${ }^{6}$, afirma que conseguem ser mais eficazes em chamar a atenção do que suas "irmãs brancas". Afinal, ele quase sempre se refere às mulheres com o epíteto de "filhas de Eva".

Os mendigos e seu recolhimento semanal de esmolas receberam algumas linhas de padre Thomas, pois descreve com admiração que eles existem de todas as cores, embora os negros predominem. Para ele, o fato de alguns virem buscar esmolas em carroças e ainda com um ajudante que se encarrega de pedir as contribuições, é motivo de profundo espanto, mas se faz mais compreensível quando ele explica que é um hábito arraigado que as famílias mais abonadas dêem esmolas semanalmente e a quebra desse compromisso, por parte delas, seria extremamente mal visto na cidade. Os aguadeiros buscando água potável no Rio Jaguarão, com suas carroças puxadas por mulas ou burros, os açougueiros vendendo carne verde pelas ruas e os vários vendedores de verduras são outro espetáculo à parte, auxiliando a tornar sua prosa vividamente interessante e capaz de prender a atenção de todos os leitores, ao longo das várias cartas em que se dedica ao cotidiano da cidade.

Outro tanto de atenção é dada à figura do reverendo protestante, com o qual se envolve em animada discussão pelos jornais e púlpitos. Ele termina vencendo a luta contra o protestante e este vai embora da cidade, para sua alegria. Entretanto, sua intolerância em relação à maçonaria só faz recrudescer, mas com eles nada há a fazer, pois boa parte da população masculina da elite pertence a esta seita. Ele entende que, de acordo com os costumes locais e sendo os maçons, para uso público, bons cristãos, falar mal deles resultaria em prejuízo para sua ordem, pois seus interlocutores não aceitariam esta situação e, deste modo, tende a calar-se. Porém, seus confidentes leitores belgas - e nós, hoje em dia, ouvimos todas as pequenas vitórias conseguidas, ou todas as atitudes maliciosas com a Igreja desses "pérfidos inimigos", tanto em Jaguarão, quanto em outras cidades do estado.

Uma questão ainda não plenamente entendida sobre seu comportamento é a falta de uma posição em relação ao positivismo, que praticamente não comparece em seus escritos. Talvez, em sua terra natal, esta ideologia não fosse conhecida ou não lhe fosse dada importância e, aqui, ele a tenha confundido com o republicanismo, o qual comenta, mas

6 Sem nunca deixar de mencionar os pés no chão, detalhe que tanto o incomoda e que atribui tanto à pobreza, como à incapacidade de acostumar os pés a calçados, mesmo que chinelas ou tamancos, por quem desde criança havia se acostumado a andar de pé no chão. 
sem emitir opinião. Contudo, sendo a elite gaúcha tão informada nesta questão, parece-nos difícil que lhe tenha escapado sua reprovação tão ácida da Igreja Católica, especialmente dos jesuítas, dos quais ele elogia os grandes esforços como educadores no país, em uma de suas cartas.

Perto do final de sua estada, começa a dar informações sobre o Estado, sua economia, sociedade e, ainda, a situação política particular da região. Demora-se sobre o coronel e líder castilhista conhecido como João Francisco, personagem do romance de Dionélio Machado, O louco do Cati. Apresenta, a seu modo, os principais horrores da revolução federalista, num olhar que parece cair muito mais sobre as sequelas, lamentações e danos que ela trouxe aos seus combatentes (sem pés, sem mãos, mutilados e aleijados de várias formas) do que ao seu lado político.

\section{As cidades e a fronteira}

Outra das descrições fundamentais do padre Thomas é sobre a fronteira e as relações tensas em alguns casos, harmoniosas em outros, entre os dois lados. Por harmoniosas, entende-se o caso da cooperação entre as duas cidades, como no caso de incêndios. Como tensas, existem as descrições sobre os guardas da fronteira, as rixas entre uruguaios e brasileiros e a repressão ao contrabando, feita pelos guardas brasileiros, armados. Contudo, os contrabandistas também trabalham às claras, às vezes, e chegam a reagir aos tiros no meio do rio, provocando alarme e debandada geral da polícia. O fato de todos andarem armados, da existência de uma certa intolerância entre brasileiros e uruguaios também contribui para conflitos pontuais, em bailes ou vendas.

$\mathrm{O}$ viver em fronteiras também obriga a formas de auxílio mutuo. Assim, o religioso nos conta que na inundação do rio Jaguarão, em julho de 1902, os habitantes de Jaguarão já esperavam, mesmo que contrariados, os pedidos de ajuda dos habitantes de Artigas/Rio Branco a qual, construída na margem mais baixa do rio, era frequentemente atingida pelas águas. Pedidos de auxílio a serem rapidamente atendidos, logo que ouvidos o espoucar de foguetes, meio muito versátil de comunicação pelas partes. Aliás, os fogos de artifício eram muito utilizados na região a todos os momentos, pois tanto serviam para abrilhantar festas, procissões e casamentos, quanto para avisos em momentos de risco. Em outra parte, nos fala que os conflitos entre blancos e colorados no país vizinho, ainda presentes naqueles anos e de forma aguda na cidade defronte, trazia consequências para o lado 
brasileiro, pois eles poderiam ter suas ruas cheias de asilados uruguaios, ou ter que prestar ajuda médica para os feridos de ambas as cores.

Percebe-se que boa parte dos conflitos, dos quais Thomas tem notícia, são internos aos gaúchos. Muitos anos depois de terminada a revolução federalista, o padre, com sua formação militar anterior, sempre era atraído para conversas com militares brasileiros e, dessa forma, narra ter sabido de várias pessoas mutiladas em ataques intermitentes, na região sul, incluindo Rio Grande, como já ocorrera em sua viagem de vinda e novamente quando de sua partida.

Durante os três anos que passou no Brasil, ele fez poucas viagens pelo Estado, entre elas a da chegada, outra ao levar alunos à capital, para fazer os exames preparatórios para as faculdades e de início de 1904, quando vai embora para a Bélgica. Passou, então, por Pelotas e Porto Alegre, as duas que lhe mereceram maior menção, já que nada de bom achou para falar sobre Rio Grande.

Porto Alegre, visitada em maio/abril de 1903, se lhe afigura estar em meio a morros, que demandam um eterno subir e descer, podendo ser feito por bondes puxados a burro, dos quais há duas companhias. Fala rapidamente de suas "várias e bem instaladas fábricas" pertencentes a alemães e, em várias ruas, esse é o idioma mais falado. Logo a seguir, entra no assunto de sua especialidade, o trabalho pastoral da Igreja, o qual the parece ter rendido muito melhores frutos na cidade, já com seis igrejas e muitos praticantes, do que em Jaguarão. O episódio de um suicídio, no hotel em que se hospedara, faz com que se abrigue junto ao colégio Anchieta, observando, portanto, de perto, as condições do ensino em Porto Alegre. Os exames preparatórios eram um dos motivos dos irmãos norbertinos terem feito sucesso com seu colégio, pois, ao que parece, conseguiram a aprovação, desde o início, de um bom número de alunos. Assim, a observação do conteúdo do exame e das formas pelas quais eles aconteciam era vital para a congregação em Jaguarão.

De Pelotas, visitada três vezes, suas descrições variam bastante. $\mathrm{Na}$ vinda, a cidade lhe surge a partir do barco e, inicialmente, se vêem as charqueadas e sua inumerável quantidade de bois para o abate, bem como os trabalhadores nos saladeiros ainda terminando a safra. Montanhas de ossos e urubus completam a cena e, acima disso, ele vê despontar as torres de duas igrejas da cidade. Um breve passeio de bonde completa a visita e apenas refere que "a cidadezinha é bonita", mas que, fora das igrejas, não viu nenhum outro edifício digno de nota. Nesse particular, deve-se dizer que padre Thomas é bem exigente, pois, em todo o Brasil, quase nenhuma obra arquitetônica lhe pareceu impressionante, e seus 
olhos bem mais se dirigem para a natureza do que para os artefatos humanos.

$\mathrm{Na}$ segunda vez, chegou de trem e ferido, após ter sofrido um acidente em uma das, a esta altura, "malditas diligências". Medicando-se na Santa Casa, hospeda-se junto aos jesuítas do Colégio Gonzaga e fala dos privilégios destes, ao terem recebido permissão governamental para fazer os exames preparatórios localmente, sem se submeterem aos perigos de uma viagem como ele, nem terem que enfrentar examinadores maçons e sua implicância contra a igreja. Após falar das cinco ou seis cervejarias locais "cujos produtos podem concorrer com as melhores cervejas belgas" (p. 313) e tecer algumas considerações sobre os estrangeiros da cidade e seu porto, ele procura o descanso para se restabelecer.

De todas, sua terceira viagem, quando de volta à Bélgica, é a mais impactante. Isso porque ele novamente passa de navio pela cidade, portanto, perto das charqueadas, em plena safra do gado e no verão. Dessa forma, recebem, no barco, inesperada e nojenta companhia. Segundo ele, Pelotas é reconhecida no país inteiro como a cidade das moscas e dos mosquitos por causa dos milhões que existem e de seus associados e a descrição que se segue faz jus a isso:

Recém havíamos almoçado e coroávamos o repasto com uma xícara do tradicional Café Santos, quando, de supetão, uma legião de moscas invadiu o vapor. Chão, paredes, teto, mesas e cadeiras ficaram, como que por encanto, cobertos de moscas. Desesperadamente as espantávamos, em volta, para ainda tentar salvar nossas xícaras de café do ataque geral, mas tudo em vão (p. 405).

Padre Thomas, contudo, não deixa de novamente fazer referência às cervejarias alemãs, aos colégios mantidos por religiosos, para meninos e meninas, e à pujança do seu porto, no qual se aconchegavam um enxame de veleiros, próprios para a navegação interna.

Na saída por Rio Grande, a cidade "não oferece nada de curioso", pelo que se contenta em relatar sua visita ao colégio dos jesuítas em construção. Temeroso por estar em um dos portos mais perigosos do mundo, padre Thomas fica muito feliz quando conseguem atravessar a barra e rumar para Florianópolis.

Em rápida conclusão, pode-se dizer que padre Thomas nos traz a visão de um outro Rio Grande do Sul, aquele das fronteiras, do cotidiano, muito mais concreto e real, cheio de pequenos detalhes importantes para os historiadores. Seu livro é muito interessante e fácil de ler, além de 
trazer um certo arejamento em visões muito científicas e arrogantes, de outros europeus, que não tiveram olhos para ver, como este, o povo em sua simplicidade e alegria.

\section{Referências}

CARDOSO, Sérgio. O olhar viajante (do etnólogo). In: NOVAES, Adauto (Org.). $O$ olhar. São Paulo: Companhia das Letras, 1988. p. 347-365.

CRUZ, Maria Cecília Velasco. Tradições negras na formação de um sindicato: sociedade de resistência dos trabalhadores em trapiche e café, Rio de Janeiro, 1905-1930. AfroAsia, UFBA, n. 24, p. 243-290.

ELIAS, Norbert. O processo civilizador. Rio de Janeiro: Jorge Zahar, 1994. v.1.

SCHOENAERS, Thomas. Três anos no Brasil. Pelotas: EDUCAT, 2003. 